\title{
Utilization of algal polysaccharides by human colonic bacteria, in axenic culture or in association with hydrogenotrophic microorganisms
}

\author{
V Rochet, A Bernalier* \\ Laboratoire de nutrition et sécurité alimentaire, Inra, domaine de Vilvert, \\ 78352 Jouy-en-Josas cedex, France
}

(Received 5 October 1996; accepted 13 January 1997)

\begin{abstract}
Summary - The ability of different hydrolytic bacteria from the human colon to grow on various algal polymers (carrageenans, Palmaria palmata xylan, ulvan, desulphated ulvan and laminaran) was investigated and the interactions between Bacteroides thetaiotaomicron and $\mathrm{H}_{2}$-utilizing microorganisms (one methanogenic archaea and an acetogenic bacterium) were studied during laminaran degradation. None of the algal polysaccharides supported the growth of any of the hydrolytic species tested, except for laminaran, which allowed substantial growth of $B$ thetaiotaomicron. This suggested that bacterial consortia were involved in algal polymer breakdown rather than one specific bacterial species. The presence of $\mathrm{H}_{2}$-utilizing microorganisms did not increase the extent of laminaran degradation by $B$ thetaiotaomicron. Whereas the decrease in formate and $\mathrm{H}_{2}$ concentrations attested to their utilization by both hydrogenotrophic microorganisms, the large increase in acetate production observed in the coculture with acetogenic bacteria was mainly due to acetogenic fermentation of sugars released during laminaran hydrolysis.
\end{abstract}

human colon / seaweed degradation / Bacteroides / $\mathbf{H}_{\mathbf{2}}$-utilizing microorganism / microbial interaction

Résumé - Utilisation de polymères algaux par les bactéries hydrolytiques du côlon humain, en culture pure ou associés à un micro-organisme hydrogénotrophe. La capacité de différentes espèces bactériennes hydrolytiques du côlon humain à croître avec des polyosides algaux (carraghénanes, xylane de Palmaria palmata, ulvanes, ulvanes désulfatés et laminaranes) comme source de carbone a été étudiée ainsi que l'effet de deux micro-organismes hydrogénotrophes (l'un méthanogène et l'autre acétogène) sur la dégradation in vitro du laminarane par Bacteroides thetaiotaomicron. Aucune des espèces hydrolytiques testées n'a été capable de croître en présence d'un des polyosides algaux étudiés à l'exception de $B$ thetaiotaomicron qui maintient sa croissance avec le laminarane.

* Correspondence and reprints.

Tel: (33) 01346527 09; fax: (33) 01346523 11; e-mail: bernalie@ jouy.inra.fr 
Des consortia bactériens sembleraient donc nécessaires à la dégradation de ces composés algaux plutôt qu' une espèce bactérienne seule. La présence d'un micro-organisme hydrogénotrophe ne s'est pas traduite par une augmentation de la quantité de laminarane dégradée par $\boldsymbol{B}$ thetaiotaomicron. La diminution des concentrations de formate et de $\mathrm{H}_{2}$ dans les deux cocultures témoigne de leur utilisation par les deux types de micro-organismes hydrogénotrophes. En revanche, la forte augmentation d'acétate observée dans la coculture avec la bactérie acétogène s'explique principalement par la fermentation homoacétique des oses issus de l'hydrolyse du laminarane.

côlon humain / dégradation des algues / Bacteroides / micro-organisme hydrogénotrophe / interaction microbienne

\section{INTRODUCTION}

Macroalgae are composed of three different classes depending on the nature of their pigments: brown (Phaeophyceae), red (Rhodophyceae) and green (Chlorophyceae) algae. Brown and red algae are the principal sources of commercial interest. They are used both as dietary constituents as well as thickening, gelling and stabilizing agents (alginates, agars, carrageenans) by the colloid industry (Jensen, 1993).

The major components of seaweeds are carbohydrates which account for approximately $50 \%$ of their dry matter, and are essentially reserve and cell-wall polysaccharides (Darcy-Vrillon, 1993; Mabeau and Fleurence, 1993). Seaweeds are particularly rich in dietary fibres of which more than $50 \%$ are water soluble (Lahaye, 1991). The higher content of soluble dietary fibres in algae compared to that observed in land plants is of particular interest. The soluble polysaccharides recognized as dietary fibres are agars, carrageenans and xylans from red seaweeds, sulfated rhamnoxyloglucuronans from green seaweeds, together with alginates and fucans from brown seaweeds. Most are gel-forming and viscous polymers. The insoluble polymers are essentially cellulose, xylans and mannans (Lahaye, 1991). Laminarans constitute the sole reserve polysaccharides which are classified as fibres.

Therefore, most algal polysaccharides cannot be broken down by human digestive enzymes, and reach the large intestine where they constitute a source of carbon and energy for the different species of anaerobic bacteria growing here. The anaerobic degradation of organic matter (from both endogenous and dietary origin) in the colon depends on the participation of different groups of microorganisms which have developed complex and diversified interactions constituting a trophic chain. Polysaccharides are broken down by microorganisms into soluble sugars that are fermented by both degrading and fermentative populations. Fermentation of these polysaccharides leads to the production of short chain fatty acids (SCFA), mainly acetate, propionate and butyrate and the gases $\mathrm{CO}_{2}$ and $\mathrm{H}_{2}$ (Macfarlane and Cummings, 1991) Hydrogen, which is derived entirely from fermentation reactions, is in part removed through its excretion in breath or flatus. The main pathway of $\mathrm{H}_{2}$ disposal however involves its reutilisation by $\mathrm{H}_{2}$-consuming microorganisms, where it is an electron donor and energy source for several reactions including dissimilatory nitrate reduction, methanogenesis, dissimilatory sulfate reduction and reductive acetogenesis (Durand et al, 1996; Bernalier et al, 1996a). The role of $\mathrm{H}_{2}$-utilizing microorganisms is fundamental for the maintenance of the overall process of organic matter degradation in anaerobic ecosystems.

The aim of the present work was to investigate the ability of different hydrolytic bacteria belonging to the dominant human flora 
to grow on various algal polymers. Furthermore, the interactions between $\mathrm{Bac}$ teroides thetaiotaomicron, one of the main polysaccharides-degrading bacteria in the human colon, and two different hydrogenotrophic species, a methanogenic archaea (Methanobrevibacter smithii) and an acetogenic bacterium (Clostridium sp, strain M5a3) isolated from human feces in our laboratory (Bernalier et al, 1996b) were studied in vitro during laminaran fermentation.

\section{MATERIALS AND METHODS}

\section{Sources of organisms}

The hydrolytic bacterial species studied were either obtained from culture collections or were isolated from human feces at the Dunn Clinical Nutrition Centre (Cambridge, UK). Ruminococcus gnavus 29149 and Ruminococcus obeum 29174 came from the American Type Culture Collection. Bacteroides thetaiotaomicron 5482, Bacteroides vulgatus 4245 and Bacteroides distasonis 4243 were kindly provided by Prof AA Salyers (University of Illinois, Urbana-Champaign, USA). Strains 22,38 identified as bifidobacteria and strains $4 \mathrm{ii}, 1 \mathrm{i}, 2 \mathrm{i}, 5 \mathrm{i}, 10 \mathrm{i}, 15 \mathrm{i}$ identified as clostridia were a gift from Dr C Michel (INRA, Nantes, France) who isolated them from batch cultures of human feces adapted to ulvan (strain 4ii) or Ulva sp.

The $\mathrm{H}_{2} / \mathrm{CO}_{2}$-utilizing acetogenic bacterium (strain M5a3) was isolated in our laboratory from a fecal sample of a non-methanogenic subject (Bernalier et al, 1996a). Strain M5a3 (DSM 10510) corresponds to a new species of the genus Clostridium (unpublished data). Methanobrevibacter smithii 861 came from the Deutsche Sammlung von Microorganismen und Zellkulturen GmbH.

\section{Media and growth conditions}

The methods used for preparing the prereduced medium and the anaerobic culture techniques were those described by Hungate (1969). The basal medium used was the semi-synthetic modified AC-21 medium (Bernalier et al, 1996c) supplemented with $1 \mathrm{mg} / \mathrm{L}$ hemin $(\mathrm{AC}-21 \mathrm{~h}$ ). Sup- plementation of basal $\mathrm{AC}-21 \mathrm{~h}$ with $10 \%$ centrifuged rumen fluid was used in some experiments. The culture media were prepared and kept under a $100 \% \mathrm{CO}_{2}$ gas phase and dispensed in $10 \mathrm{~mL}$ into serum-capped tubes (Bellco Glass Inc, Vineland, NJ, USA).

\section{Utilization of algal substrates by hydrolytic bacterial species}

The utilization of the different algal substrates by colonic microorganisms was determined using basal AC-21 h medium containing $2 \mathrm{~g} / \mathrm{L}$ of seaweed product as the sole carbon source. The seaweed products tested were lambda, iota and kappa carrageenans, Palmaria palmata xylan, ulvan and desulfated ulvan, which were kindly provided by Dr M Lahaye (INRA, Nantes, France) and laminaran (Sigma). Potato soluble starch from (Sigma) was used as a bacterial growth control.

The bacterial inocula consisted of $0.3 \mathrm{~mL}$ of a $20 \mathrm{~h}$ culture grown on glucose $(2 \mathrm{~g} / \mathrm{L}) \mathrm{AC}-21 \mathrm{~h}$ medium. Cultures were incubated at $37^{\circ} \mathrm{C}$ and bacterial growth was followed over 8 days by measuring the absorbance at $600 \mathrm{~nm}\left(\mathrm{OD}_{600}\right)$ with a Spectronic 20D spectrophotometer (Bioblock Scientific, Illkirsh, France). The ability of algal products to support growth of the strains was considered as positive when the culture could be maintained on the same substrate after three transfers. In addition, the $\mathrm{OD}_{600}$ of the culture had to be twice that observed on the basal substrate free medium after $48 \mathrm{~h}$ incubation at $37^{\circ} \mathrm{C}$.

\section{Coculture studies with Bacteroides thetaio- taomicron and $\mathrm{H}_{2} / \mathrm{CO}_{2}$-utilizing micro- organisms}

Coculture experiments were done using the $\mathrm{AC}$ $21 \mathrm{~h}$ medium containing laminaran $(5 \mathrm{~g} / \mathrm{L})$ as sole carbon source. Monocultures of $B$ thetaiotaomicron and cocultures were inoculated with $0.2 \mathrm{~mL}$ of a $4 \mathrm{~h}$ culture of the hydrolytic bacterium, exhibiting an $\mathrm{OD}_{600}$ equivalent to 0.3 on the laminaran growth medium. The acetogenic strain inoculation was $0.3 \mathrm{~mL}$ of a $24 \mathrm{~h}$ culture on glucose growth medium. Cocultures with $B$ thetaiotaomicron and Clostridium sp strain M5a3 were performed by inoculating the two strains 
simultaneously. In contrast, the methanogenic strain was inoculated 5 days before the hydrolytic bacterium in the studies with $B$ thetaiotaomicron and $M$ smithii. The preculture of $M$ smithii ( $0.5 \mathrm{~mL}$ inoculum per tube) was carried out under a gas phase composed of $\mathrm{H}_{2} / \mathrm{CO}_{2}(60 / 40$, v/v) at an initial pressure of $202 \mathrm{kPa}$. When the methanogenic preculture had reached an $\mathrm{OD}_{600}$ of 0.2 (after 5 days incubation), the tubes were flushed with $100 \% \mathrm{CO}_{2}$ to eliminate the remaining $\mathrm{H}_{2}$ and $\mathrm{CH}_{4}$ produced by the methanogenic organism. The hydrolytic bacterium was subsequently inoculated into these coculture tubes. Monocultures and cocultures were incubated at $37^{\circ} \mathrm{C}$ for $2,3,4,6$ and 8 days. After incubation, bacterial growth was stopped by rapidly freezing the cultures at $-20^{\circ} \mathrm{C}$.

Hydrogen and methane concentrations in the head space gas of each culture tube were measured by gas chromatography as described by Czerkawski and Clapperton (1968). The bacterial cultures were then centrifuged at $12000 \mathrm{~g}$ for $20 \mathrm{~min}$ at $4^{\circ} \mathrm{C}$ and the supernatants were stored at $-20^{\circ} \mathrm{C}$ after addition of $10 \mu \mathrm{LHgCl}_{2}$. The soluble fermentation products were measured by capillary gas chromatography, after conversion to tertiary butyldimethylsilyl derivates according to the method of Richardson et al (1989).

The residual laminaran contained in the supernatans was hydrolysed with $\mathrm{H}_{2} \mathrm{SO}_{4}, 15 \mathrm{M}$ at $4{ }^{\circ} \mathrm{C}$ for $1 \mathrm{~min}$, then at $20^{\circ} \mathrm{C}$ for $2 \mathrm{~min}$ and finally at $100^{\circ} \mathrm{C}$ for $3 \mathrm{~min}$. The released hexoses and the residual sugars were further measured colori- metrically using the cysteine-sulfuric acid method described by Dische (1963). The amount of glucose residues remaining in the cultures was determined enzymatically using glucose $6 \mathrm{P}$ dehydrogenase (Boehringer-Mannheim).

\section{RESULTS}

\section{Utilization of seaweed polysaccharides by hydrolytic bacteria}

Algal polysaccharides failed to support the growth of any of the Bacteroides and Ruminococcus species studied, with the exception of laminaran, which allowed substantial growth of $B$ thetaiotaomicron $\left(\mathrm{OD}_{600}=0.695 \pm 0.06\right.$ on laminaran- $\mathrm{AC}$ $21 \mathrm{~h}$ medium versus $0.277 \pm 0.01$ on substrate-free control medium) (table I). However, the growth of this bacterial species on laminaran was significantly slower than that observed on soluble starch. This last polysaccharide also supported the growth of the largest number of bacterial species tested (table I). Among the eight strains isolated from human feces adapted to grow on seaweed-products Ulva sp and ulvan, only one Clostridium species (10i) could be maintained on xylan from Palmaria palmata,

Table I. Growth of human colonic bacterial species on different algal substrates.

\begin{tabular}{lccccc} 
Growth substrates & $\begin{array}{c}\text { Bacteroides } \\
\text { thetaiotaomicron }\end{array}$ & $\begin{array}{c}\text { Bacteroides } \\
\text { vulgatus }\end{array}$ & $\begin{array}{c}\text { Bacteroides } \\
\text { distasonis }\end{array}$ & $\begin{array}{c}\text { Ruminococcus } \\
\text { gnavus }\end{array}$ & $\begin{array}{c}\text { Ruminococcus } \\
\text { obeum }\end{array}$ \\
\hline Lambda carrageenans & $-{ }^{\mathrm{a}}$ & - & - & - & $\mathrm{nd}$ \\
Iota carrageenans & - & - & - & - & nd \\
Kappa carrageenans & - & - & - & - & nd \\
Laminaran & $++^{\mathrm{b}}$ & - & - & - & - \\
Ulvan & - & - & - & - & - \\
Desulfated ulvan & - & - & - & - & - \\
Palmaria palmata $x y l a n$ & - & - & - & - & - \\
Potato soluble starch & $++^{\mathrm{c}}$ & + & + & + & - \\
\hline
\end{tabular}

$a_{-}$: same $\mathrm{OD}_{600}$ in control and test media. ${ }^{\mathrm{b}}+: \mathrm{OD}_{600}$ in test medium is twice the $\mathrm{OD}_{600}$ in control medium. ${ }^{c}++: \mathrm{OD}_{600}$ in test medium is three times higher than $\mathrm{OD}_{600}$ in control medium. nd: not determined

Each measurement $\left(\mathrm{OD}_{600}\right)$ was performed three times, with triplicate cultures observed each time. Test medium contained $2 \mathrm{~g} / \mathrm{L}$ of substrate whereas control medium was a substrate free medium. 
ulvan and desulfated ulvan, although growth was poor (data not shown). Ulvan and xylan from Palmaria palmata also supported moderate growth of Clostridium strain $15 i$ and Clostridium strain $2 \mathrm{i}$. In contrast, none of the Bifidobacterium strains tested utilized algal polymers as carbon sources. Supplementation of the semi-synthetic modified AC- $21 \mathrm{~h}$ medium with $10 \%$ rumen fluid did not improve the ability of any of the bacteria to grow on algal substrates (data not shown).

From these results, $B$ thetaiotaomicron was selected for further studies on the degradation of laminaran, in association with $\mathrm{H}_{2}$ utilizing microorganisms.

\section{Laminaran degradation by $B$ thetaio- taomicron in axenic cultures and cocul- tures with $\mathrm{H}_{2} / \mathrm{CO}_{2}$-utilizing microorgan- isms}

The extent of laminaran utilization by $B$ thetaiotaomicron was not increased by the presence of any of the hydrogenotrophic microorganisms (fig 1). Although the initial rate of laminaran degradation was sig-

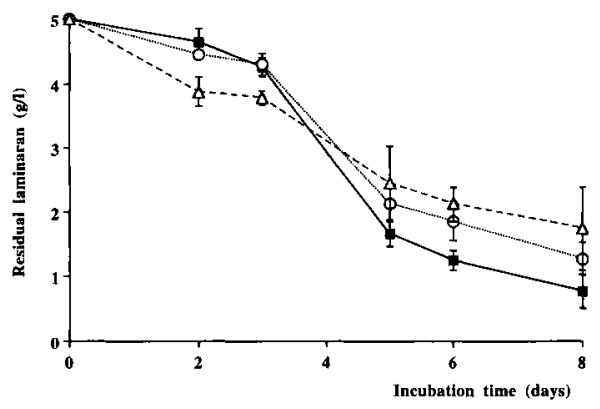

Fig 1. Kinetics of laminaran degradation by Bacteroides thetaiotaomicron in monoculture (ש) or in cocultures with the acetogenic bacterium, Clostridium sp strain M5a3 (O) or with Methanobrevibacter smithii $(\Delta)$.

Each point represents the mean value of three determinations \pm standard error. nificantly higher in the presence of $M$ smithii $(1.13 \pm 0.23 \mathrm{~g}$ of laminaran degraded in the coculture versus $0.38 \pm 0.21 \mathrm{~g}$ in the monoculture after 2 days of incubation), the final extent of substrate breakdown ( 8 days of incubation) was significantly lower in the coculture than in the monoculture. In coculture with the $\mathrm{H}_{2} / \mathrm{CO}_{2}$-utilizing acetogenic strain, the initial rate of laminaran degradation was similar to that of the monoculture (fig 1). A small decrease in the total amount of substrate used was observed after 8 days of incubation in this coculture compared to the monoculture (fig 1). Glucose did not accumulate in the acetogenic coculture as it did in the monoculture, while this substrate was found in higher concentrations in the presence of the methanogen $(0.28 \pm$ $0.08 \mathrm{~g} / \mathrm{L}$ versus $0.73 \pm 0.23 \mathrm{~g} / \mathrm{L}$ respectively).

In the axenic culture of $B$ thetaiotaomicron, the major end-products of laminaran fermentation were acetate, propionate, succinate, formate and $\mathrm{H}_{2}$ (table II). When Methanobrevibacter smithii was cocultivated with $B$ thetaiotaomicron, methane was detected in the gas phase of the coculture whereas $\mathrm{H}_{2}$ and formate did not accumulate (table II). Acetate was found in greater amounts in coculture than in axenic culture. Similarly, acetate production increased while formate and $\mathrm{H}_{2}$ concentrations decreased in coculture with the acetogenic bacteria (table II). Trace amounts of $\mathrm{H}_{2}$ however could be detected in the gas phase of the coculture with the acetogenic strain, even after 8 days of incubation, whereas this gas totally disappeared in the presence of $M$ smithii (table II). In contrast, higher acetate production was found in coculture with the acetogen than in the methanogenic association.

Analysis of laminaran fermentation products in the Bacteroides - acetogen coculture showed that the acetate production mainly increased after 2 days of incubation, while $\mathrm{H}_{2}$ and formate no longer accumulated. The small amounts of ethanol and lac- 
Table II. End-products of laminaran fermentation (obtained after 8 days of incubation) formed by Bacteroides thetaiotaomicron in axenic culture or in coculture with Methanobrevibacter smithii or with the acetogenic bacterium, Clostridium sp strain M5a3.

\begin{tabular}{lccc}
\hline $\begin{array}{c}\text { End-products } \\
\text { (mM/loOmM of } \\
\text { hexoses fermented })\end{array}$ & B thetaiotaomicron & $\begin{array}{c}\text { B thetaiotaomicron } \\
\text { Clostridium strain M5a3 }\end{array}$ & $\begin{array}{c}\text { B thetaiotaomicron } \\
+ \text { M smithii }\end{array}$ \\
\hline Formate & $6.0 \pm 0.1$ & 0.0 & 0.0 \\
Acetate & $80.5 \pm 6.6$ & $124.4 \pm 15.0$ & $97.0 \pm 9.3$ \\
Propionate & $48.5 \pm 0.6$ & $43.0 \pm 5.0$ & $54.5 \pm 19.0$ \\
Succinate & $5.2 \pm 2.9$ & $4.0 \pm 0.3$ & $6.3 \pm 8.6$ \\
$\mathrm{H}_{2}$ & $1.6 \pm 0.3$ & $0.6 \pm 0.1$ & 0.0 \\
$\mathrm{CH}_{4}$ & 0.0 & 0.0 & $7.9 \pm 0.5$ \\
$\% \mathrm{C}$ recovery & 60 & 69 & 70 \\
\hline
\end{tabular}

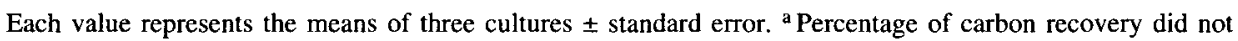
take into account cell carbon.

tate produced by $B$ thetaiotaomicron in monoculture ( 1.0 and $0.5 \mathrm{mM}$ respectively) were not detected in the two cocultures (data not shown). In contrast, propionate and succinate productions did not appear to be affected by coculture with hydrogenotrophic microorganisms (table II).

\section{DISCUSSION}

This study showed that most of algal polysaccharides tested, from three different classes of seaweeds, failed to support the growth of the majority of hydrolytic species from the dominant human microflora. The capacity of bacterial strains to grow, in vitro, with complex algal polysaccharides as carbon sources has not been studied extensively, although more work has been done on the ability of the whole fecal flora to ferment these substrates (Michel and Macfarlane, 1996).

We demonstrated that the three different types of carrageenans from red seaweeds did not support significant growth for any of the bacterial species tested. Similarly, Saly- ers et al (1977b) have shown the inability of a pure culture of intestinal bacteria to ferment carrageenans in vitro. Our results were consistent with the previous studies reported by Michel and Macfarlane (1996) who demonstrated that the human colonic microflora could chemically modify carrageenans rather than metabolize them.

In contrast, xylan from Palmaria palmata appeared to be highly fermented within the first $6 \mathrm{~h}$ of incubation with a human fecal microflora (Lahaye et al, 1993). However, only a few Clostridium strains (2i, 10i, 15i) showed any ability to grow on this substrate. Salyers et al (1981) observed that oligomers of different sizes were released from nonalgal xylan by pure cultures of Bacteroides ovatus and Bacteroides eggerthii. However, the Bacteroides species tested in our study failed to show the same ability to degrade xylan from seaweed.

Adaptation of the fecal microflora to grow on ulvan or desulfated ulvan from Ulva sp did not enhance the ability of the predominant bacterial species to use them as growth substrates. Only two clostridia (10i and 15i), isolated from these adapted 
microbiotas, were able to grow on these polysaccharides. Similarly, Bobin-Dubigeon et al (1994) and Durand et al (unpublished data) observed that ulvan and desulfated ulvan were poorly fermented by human fecal flora.

Since most of these algal polymers are chemically modified or fermented by mixed populations of intestinal bacteria, while pure cultures of the predominant bacteria in these communities failed to grow with these substrates, it is suggested that breakdown of these algal polysaccharides requires the involvement of more than one bacterial species. Due to the unusual chemical composition of these algal polymers, it is likely that the contribution of several polymerdegrading species may be necessary to significantly degrade these substrates. This would explain our inability to find pure bacterial cultures capable of growing efficiently on these algal polymers.

Laminaran was the sole algal polysaccharide able to support a substantial growth of Bacteroides thetaiotaomicron. This substrate has previously been shown to be highly fermented by the human fecal flora (Michel et al, 1996). In earlier studies, laminaran degrading bacteria were mainly found to belong to the genus Bacteroides (Salyers et al, 1977a, b). These bacteria possess all of the cell-bound inducible laminarases and $\beta$-glucosidases (Salyers et al, 1977c) necessary to fully degrade this polymer which is composed of $\beta-1,3$ linked glucans. These have a low degree of polymerization and contain $\beta-1,6$ linkages and mannitol residues on the reducing ends (Michel and Macfarlane, 1996). The main laminaran degradation product by strains of $B$ thetaiotaomicron was glucose (Salyers et al, 1977c).

The presence of $\mathrm{H}_{2} / \mathrm{CO}_{2}$-utilizing microorganisms did not improve laminaran degradation by $B$ thetaiotaomicron. Similarly, no enhancement of plant cell wall degradation by Bacteroides species was shown to occur in the presence of $M$ smithii (Stewart et al, 1990). While Morvan et al (1996) also reported a similar lack of effect on fermentation with some rumen acetogenic strains, on the rate of cellulose breakdown by $R$ flavefaciens, methanogens and acetogens were shown to increase cellulose degradation by rumen fungi and Ruminococcus albus respectively (Bernalier et al, 1991; Morvan et al, 1996). This enhancement of polysaccharide utilization by $\mathrm{H}_{2}$-consuming microorganisms is known to be due to a reduction in the $\mathrm{H}_{2}$ partial pressure by $\mathrm{H}_{2}$ consuming syntrophy (Wolin and Miller, 1983). In our experiments, the absence of effect of hydrogenotrophic microorganisms on laminaran degradation by $B$ thetaiotaomicron could be explained by the fact that this hydrolytic species is a weak $\mathrm{H}_{2}$ producer. Therefore, the elimination of $\mathbf{H}_{2}$ in the coculture was probably too low to have a major influence on polysaccharide degradation. Similarly, utilization of $\mathrm{H}_{2}$ by $M$ smithii did not induce metabolic shifts in $B$ thetaiotaomicron. Because the methane production remained very low, it is likely that the growth of the methanogen in the coculture was limited, probably due to a low availability of $\mathrm{H}_{2}$ and formate. It is therefore difficult to assume that the small increase in acetate production by $B$ thetaiotaomicron was a consequence of $\mathrm{H}_{2}$ re-utilization by the methanogens as was demonstrated with $R$ albus and rumen fungi (Wolin and Miller, 1983; Bernalier et al, 1991; Morvan et al, 1996). In contrast, large amounts of acetate were observed in coculture with the acetogenic strain.This increase in acetate production however appeared to be mainly due to sugar fermentation by the acetogen. Glucose released from laminaran degradation by $B$ thetaiotamicron could undoubtedly be consumed by the acetogenic organism which was previously shown to form large amounts of acetate from this sugar (Bernalier et al, 1996b). Acetate was also derived in part from the acetogenic metabolism of $\mathrm{H}_{2}$ and formate, mainly dur- 
ing the earlier incubation times of the cocultures. This demonstrated the ability of acetogenic bacteria from the human colon to metabolize $\mathrm{H}_{2}$ formed by hydrolytic species. However, these acetogenic bacteria appeared less efficient than methanogens in their ability to re-utilize $\mathrm{H}_{2}$, since trace amounts of this gas remained in the coculture. The important nutritional versatility of acetogens compared to methanogens, which can only use a restricted range of substrates, may influence their capacity to utilize $\mathrm{H}_{2}$. Regulation of $\mathrm{H}_{2}$ metabolism by organic compounds in colonic acetogenic bacteria may occur as shown with other acetogens such as Eubacterium limosum and Sporomusa termitida (Sharak-Genthner and Bryant, 1987; Breznak and Blum, 1991). Therefore, the role of acetogenic bacteria in $\mathrm{H}_{2}$ scavenging in the colon ecosystem may largely be dependent on carbohydrate availability. The influence of organic substrates on the metabolism of $\mathrm{H}_{2}$ by colonic acetogens is now under study in our laboratory.

\section{ACKNOWLEDGEMENT}

We wish to thank Dr GT Macfarlane for his assistance in preparing this manuscript, and $\mathrm{P}$ Beaumatin for his skilled technical assistance in the chromatography analyses. This work was financially supported by a grant from the EC contract AIR 1 CT 92518.

\section{REFERENCES}

Bernalier A, Fonty G, Gouet P (1991) Cellulose degradation by two rumen anaerobic fungi in monoculture or in coculture with rumen bacteria. Anim Feed Sci Technol 32, 131-136

Bernalier A, Lelait M, Rochet V, Grivet JP, Gibson GR, Durand M (1996a) Acetogenesis from $\mathrm{H}_{2}$ and $\mathrm{CO}_{2}$ by methane- and non methane-producing human colonic bacterial communities. FEMS Microbiol Ecol 19, 193-202

Bernalier A, Rochet V, Leclerc M, Doré J, Pochard P (1996b) Diversity of $\mathrm{H}_{2} / \mathrm{CO}_{2}$-utilizing acetogenic bacteria from feces of non methane-producing humans. Curr Microbiol 33, 94-99

Bernalier A, Willems A, Lelerc M, Rochet V, Collins MD (1996c) Ruminococcus hydrogenotrophicus sp nov, a new $\mathrm{h}_{2} / \mathrm{CO}_{2}$-utilizing acetogenic bacterium isolated from human feces. Arch Microbiol $166,176-183$

Bobin-Dubigeon C, Ray B, Lahaye M, Barry JL, Beaumatin P, Durand M (1994) Relationship between human colonic bacterial degradability and chemical structure of dietary fibres from the marine green algae: Ulva sp. Proc of the 4th Int Workshop on Oligo and Polysaccharides 21, 62

Breznak JA, Blum JS (1991) Mixotrophy in the termite gut acetogen, Sporomusa termitida. Arch Microbio 156, 105-110

Czerkawski JW, Clapperton JL (1968) Analysis of gases produced by metabolism of microorganisms. Lab Pract 17, 994 cont 1012-1013

Darcy-Vrillon B (1993) Nutritional aspects of the developing use of macroalgae for human food industry. Int J Food Sci Nutr 44, S23-S35

Dische Z (1963) New color reactions for determination of sugars in polysaccharides. Meth Biochem Anal II, 313-358

Durand M, Bernalier A, Duré J (1996) Hydrogen metabolism in the colon. In: Dietary fibre and fermentation in the colon. Proc Cost 92 Workshop, Espoo, Finland

Hungate RE (1969) A roll-tube method for cultivation of strict anaerobes. In: Methods in microbiology (JR Norris, DW Gibons, eds), Academic Press, New York, USA, 117-132

Jensen A (1993) Present and future needs for algae and algal products. Hydrobiologia 260-261, 15-23

Lahaye M (1991) Marine algae as sources of fibres: determination of soluble and insoluble dietary fibre content in some 'sea vegetables'. J Sci Food Agric 54, 587-594

Lahaye M, Michel C, Barry JL (1993) Chemical, physico-chemical and in vitro fermentation characteristics of dietary fibres from Palmaria palmata L, Kuntze. Food Chem 47, 29-36

Mabeau S, Fleurence J (1993) Seaweed in food products: biochemical and nutritional aspects. Trends Food Sci Technol 4, 103-107

Macfarlane GT, Cummings JH (1991) The colonic flora: fermentation and large bowel digestive function. In: The large intestine: physiology, pathophysiology and disease (SF Philips, JH Pemberton, RG Shorter, eds), Raven Press, New York, USA, 51-92

Michel C, Macfarlane GT (1996) Digestive fates of soluble polysaccharides from marine macroalgae: involvement of the colonic microflora and physiological consequences for the host. $J$ Appl Bacteriol $80,349-369$ 
Michel C, Lahaye M, Bonnet C, Mabeau S, Barry JL (1996) In vitro fermentation by human faecal bacteria of total and purified dietary fibres from brown seweeds. Br J Nutr 75, 263-280

Morvan B, Rieu-Lesme F, Fonty G, Gouet Ph (1996) In vitro interactions between rumen $\mathrm{H}_{2}$-producing cellulolytic microorganisms and $\mathrm{H}_{2}$-utilizing acetogenic and sulfate-reducing bacteria. Anaerobe 2 , $175-180$

Richardson AJ, Calder AG, Stewart CS, Smith A (1989) Simultaneous determination of volatile and non-volatile acidic fermentation products of anaerobes by capillary gas chromatography. Lett Appl Microbiol 9, 5-8

Salyers AA, Vercelloti JR, West SEH, Wilkins TD (1997a) Fermentation of mucin and plant polysaccharides by strains of Bacteroides from the human colon. Appl Environ Microbiol 33, 319-322

Salyers AA, West SEH, Vercelotti JR, Wilkins TD (1977b) Fermentation of mucin and plant polysaccharides by anaerobic bacteria from the human colon. Appl Environ Microbio 34, 529-533
Salyers AA, Palmer JK, Wilkins TD (1977c) Laminarinase ( $\beta$-glucanase) activity in Bacteroides from the human colon. Appl Environ Microbiol 33, 1118 1124

Salyers AA, Gherardini F, O'Brien M (1981) Utilization of xylan by two species of human colonic $\mathrm{BaC}$ teroides. Appl Environ Microbiol 41, 1065-1068

Sharak-Genthner BR, Bryant MP (1987) Additional characteristics of one-carbon-compound utilization by Eubacterium limosum and Acetobacterium woodii. Appl Environ Microbiol 53, 471-476

Stewart CS, Richardson AJ, Douglas RM, Rumney CJ (1990) Hydrogen transfer in mixed cultures of anaerobic bacteria and fungi with Methanobrevibacter smithii. In: Microbiology and biochemistry of strict anaerobes involved in interspecies hydrogen transfer (JP Belaich, M Bruschi, JL Garcia, eds), Plenum Press, New York, USA

Wolin MJ, Miller TL (1983) Carbohydrate fermentation. In: Human intestinal microflora in health and disease (DJ Hentges, ed), Academic Press, New York, USA, 142-165 